\title{
Oxidative Dehydrogenation of n-Butane over LaV Catalysts Supported on $\mathrm{TiO}_{2}$
}

\author{
Le Minh Cam, Ngo Duc Huyen, and Nguyen Ngoc Ha \\ Division of Theoretical and Physical Chemistry, Faculty of Chemistry, Ha Noi National University of Education, \\ 136 Xuan Thuy Road-Cau Giay-Ha Noi, Vietnam \\ Correspondence should be addressed to Le Minh Cam; camlm@hnue.edu.vn
}

Received 2 May 2013; Revised 26 July 2013; Accepted 2 August 2013

Academic Editor: Sedat Yurdakal

Copyright (C) 2013 Le Minh Cam et al. This is an open access article distributed under the Creative Commons Attribution License, which permits unrestricted use, distribution, and reproduction in any medium, provided the original work is properly cited.

\begin{abstract}
The catalytic performance of vanadia catalysts with $15 \mathrm{wt} \% \mathrm{~V}$ supported on $\mathrm{TiO}_{2}$ and $\left(15 \mathrm{wt} \% \mathrm{~V}+4.6 \mathrm{wt} \% \mathrm{La}\right.$ ) supported on $\mathrm{TiO}_{2}$ in oxidative dehydrogenation $(\mathrm{ODH})$ of n-butane was investigated. The catalysts were characterized by means of TPD-NH, $\mathrm{TPR}_{3} \mathrm{H}_{2}$, UV-Vis, and BET. Testing of samples showed that vanadia catalysts were active for the reaction. It was found that La doping of $\mathrm{V} / \mathrm{TiO}_{2}$ catalyst had a negative effect on the dispersion of $\mathrm{V}$ species and led to formation of $\mathrm{V}_{2} \mathrm{O}_{5}$ clusters. This resulted in a loss of activity. Although slight improvement of selectivity was observed in comparison to undoped $\mathrm{V} / \mathrm{TiO}_{2}$ samples due to lower acidity of La-doped $-\mathrm{V} / \mathrm{TiO}_{2}$, this could not compensate the loss of activity and finally did not lead to higher butene yields.
\end{abstract}

\section{Introduction}

Oxidative dehydrogenation of light alkanes has been a research topic of consistent interest from the 1980s [1-3]. The presence of oxygen raises the thermodynamic restrictions of dehydrogenation, and the exothermic character of the reaction renders it an energetically efficient process $[4,5]$. The development of efficient heterogeneous catalysts for the oxidative dehydrogenation of alkanes is of great importance because of the economic benefits of using light alkanes for the production of important base chemicals [6,7]. In order to make the process commercially feasible, the main objective is to maximize the selectivity to alkenes, a significant issue, since the deep oxidation of alkanes and alkenes (reaction products) is thermodynamically favoured [8-11]. Experimental studies have proposed that the $\mathrm{ODH}$ reaction of $\mathrm{C}_{2}-\mathrm{C}_{4}$ alkane over transition metal based catalysts occurs following a Mars-van Krevelen redox mechanism [12] in which surface catalytic sites are reduced by hydrocarbon with participation of the lattice oxygen and followed by reoxidation with adsorbed $\mathrm{O}_{2}$ from the gas phase. It is well known that the catalyst behavior depends on a number factors, such as the chemical nature of the active species, the redox properties, and the acid-base character, which in turn depend on transition metal loading, dispersion, and support effects [13].
In case of butane $\mathrm{ODH}$, vanadium supported catalysts are considered good catalysts, and vanadium appears to be the selective catalytic site. The coordination of vanadium in the active centres and the density of the active sites belong to the most important factors determining the catalytic performance of $\mathrm{V}$ catalysts. It has been postulated in the literature that tetrahedrally coordinated $\mathrm{V}$ centres are more selective but less active than octahedral ones [14]. However, there are discrepancies between different authors whether isolated $\mathrm{VO}_{4}$ tetrahedra are more effective than units possessing $\mathrm{V}-\mathrm{O}-\mathrm{V}$ entities. The concentration of vanadium phase on the catalyst surface depends on the method of preparation and on the nature and amounts of supports or promoters eventually added to that active phase [15-19]. Very good results for vanadium dispersion and catalytic properties have been obtained by preparing the $\mathrm{TiO}_{2}-\mathrm{SiO}_{2}$ support by grafting [20]. The literature provides some information on both the method of anchoring vanadium on $\mathrm{SiO}_{2}$ and $\mathrm{TiO}_{2}-\mathrm{SiO}_{2}$ and the properties of the obtained catalysts, but there is very little information about the vanadium alkoxidesupport interaction, the relationship between dispersion and vanadium load, the amount of adsorbed vanadium corresponding to the monolayer, and the effect of calcination on surface modification. Lakshmi et al. [21] have used the sol-gel method to prepare vanadium catalysts supported on 
$\mathrm{TiO}_{2}-\mathrm{SiO}_{2}$ and $\mathrm{Zr}_{2} \mathrm{O}-\mathrm{SiO}_{2}$. Murgia et al. [15] suggested that a preparation method, which causes the vanadium to be distributed homogeneously at the surface and in the bulk, was preferred over a method which deposits vanadium only at the surface. The investigation of the catalytic properties of vanadia supported catalysts in propane ODH showed that more selective catalysts were obtained on basic metal oxide supports [13]. The presence of basic sites enhances the fast desorption of the produced olefins from the catalytic surface, resulting in higher selectivities. Furthermore, Galli et al. [22] demonstrated that doping vanadia catalysts with basic promoters has a beneficial effect in $\mathrm{n}$-butane $\mathrm{ODH}$ by increasing the olefin selectivity.

It is well know that titania allows to obtain a very good dispersion of $\mathrm{V}_{2} \mathrm{O}_{5}$ on its surface [16]. The literature data $[23,24]$ reported high activity of the $\mathrm{V}_{2} \mathrm{O}_{5} / \mathrm{TiO}_{2}$ system in the oxidative conversion of propane at relatively low temperature (500-600 K). The addition of potassium to the $\mathrm{TiO}_{2}$, in particular anatase, provides an optimal chemical environment for the vanadium oxide catalytic action. Grzybowska et al. [24] suggested that the potassium hinders the formation of the electrophilic $\mathrm{O}^{-}$species responsible for total oxidation of hydrocarbon. The butane oxidation over both monolayer and multilayer vanadia on $\mathrm{TiO}_{2}$ has been reported $[25,26]$.

In the present paper, vanadia catalysts prepared by impregnating ammonium vanadate on a titania support were investigated. We report catalytic results obtained with $15 \% \mathrm{~V}$ catalyst supported on $\mathrm{TiO}_{2}$ for the oxidative dehydrogenation $(\mathrm{ODH})$ of $\mathrm{n}$-butane. Our goal was to examine the effect of active metal at loadings exceeding a theoretical monolayer coverage. To study the effect of promoter on the catalytic performance, a sample of $\mathrm{V} / \mathrm{TiO}_{2}$ with addition of $5 \mathrm{wt} \%$ $\mathrm{La}_{2} \mathrm{O}_{3}$ (equivalent to $4.6 \mathrm{wt} \% \mathrm{La}$ ) was prepared. The reason for choosing $\mathrm{La}$ is to investigate the effect of La doping on the acid-base property of the catalyst. Due to the basicity of $\mathrm{La}_{2} \mathrm{O}_{3}$ [27] we expect the catalytic behaviour of the La-containing $\mathrm{V} / \mathrm{TiO}_{2}$ to be different from that of La-free $\mathrm{V} / \mathrm{TiO}_{2}$.

\section{Experimental}

2.1. Catalysts Preparation and Characterization. A commercial $\mathrm{TiO}_{2}$ (anatase Aldrich) was used as a support. Vanadium oxide was deposited on the support by wet impregnation using aqueous $\mathrm{NH}_{4} \mathrm{VO}_{3}$ (Merck) solution. Prior to impregnation the $\mathrm{TiO}_{2}$ support was calcined at $600^{\circ} \mathrm{C}$ for 3 hours. An aqueous solution of ammonium metavanadate was prepared and heated slowly. Oxalic acid (Merck) was added to the solutions $\left(\mathrm{NH}_{4} \mathrm{VO}_{3}\right.$ /oxalic acid $=(1 / 2)$ molar $)$ to ensure dissolution of precursor. The nominal weight loading of $\mathrm{V}$ was $15 \mathrm{wt}$.\%. This solution was then added to an aqueous $\mathrm{TiO}_{2}$ slurry. The resulting solution was stirred and heated until all the water was evaporated. Sample was dried overnight and calcined in air at $600^{\circ} \mathrm{C}$ for 4 hours. The catalyst is denoted by VT. LaV-containing $\mathrm{TiO}_{2}$ was prepared from slurries containing aqueous solutions of ammonium metavanadate and lanthanum chloride (Aldrich). The solid obtained was then heat-treated in flow oxygen at $600^{\circ} \mathrm{C}$ for 4 hours (named as $\mathrm{LaVT}$ ). The nominal weight loading of $\mathrm{La}_{2} \mathrm{O}_{3}$ was $5 \mathrm{wt} \%$.
Powder X-ray diffraction (XRD) patterns were obtained using a BRUCKER D8-Advance 5005 diffractometer and $\mathrm{Cu}$ $\mathrm{K} \alpha$ radiation.

Specific surface areas were measured by the multipoint BET analysis method using $\mathrm{N}_{2}$ adsorption isotherms at $77 \mathrm{~K}$. The measurement was performed on TriStar 3000 analyser (Micromeritics).

Temperature programmed reduction (TPR) experiments with $\mathrm{H}_{2}$ were carried out in a gas flow system. $\mathrm{NH}_{3}$ temperature programmed desorption $\left(\mathrm{NH}_{3}-\mathrm{TPD}\right)$ was used to determine the acid properties. The $\mathrm{H}_{2}-\mathrm{TPR}$ and $\mathrm{NH}_{3}$-TPD experiments were carried out using a Micromeritics model AutoChem II 2920. UV-Vis spectra of fresh catalysts were collected using a Cary 5000 Varian equipment.

2.2. Catalytic Tests. ODH of $\mathrm{n}$-butane was performed in a fixed-bed quartz tubular reactor at atmospheric pressure and under steady state conditions. The catalyst samples $(0.2 \mathrm{~g}$ with a 0.5 to $0.7 \mathrm{~mm}$ particle size) and silicon carbide were packed into the reactor to maintain a constant volume in the catalytic bed. The flow rate was $32 \mathrm{~mL} / \mathrm{min}$, and the feed comprised a mixture of n-butane, oxygen, and nitrogen with a volume ratio of $3: 1: 6$. The reaction temperature range varied between $400^{\circ} \mathrm{C}$ and $550^{\circ} \mathrm{C}$ to achieve different conversion levels. Reactants and reaction products were analyzed in line using Trace Gas Chromatograph Ultra RGA (Thermo Scientific) equipped with a thermal conductivity detector (TCD). Three columns in a series-bypass configuration were used in the analysis: BEEA, $27.5 \%$ on Chromosorb PAW, Hayesep Q, and Mol Sieve 5A. Conversions $(C)$ and the selectivities $(S)$ to the reaction products were defined as follows:

$$
\begin{gathered}
C=\left(\frac{\text { mol }_{\text {n-butane }} \text { reacted }}{\text { mol }_{\text {n-butane }} \text { in the feed }}\right) \times 100, \\
S=\left(\frac{\text { mol }_{\text {n-butane }} \text { converted to } i}{\text { mol }_{\text {n-butane }} \text { reacted }}\right) \times 100,
\end{gathered}
$$

where $i=\mathrm{C}_{4} \mathrm{H}_{8}, \mathrm{CO}, \mathrm{CO}_{2}$, and others $\left(\mathrm{CH}_{4}, \mathrm{C}_{2} \mathrm{H}_{6}, \mathrm{C}_{3} \mathrm{H}_{8}\right.$, $\mathrm{C}_{3} \mathrm{H}_{6}$, etc.).

Blank runs carried out in the empty-volume reactor at $550^{\circ} \mathrm{C}$ allowed ruling out the occurrence of gas-phase reactions to a significant extent at the experimental conditions used for the activity tests. The dehydrogenation of n-butane had also been performed on the catalysts in the absence of oxygen in the feed. The obtained conversions can be negligible $(<5 \%)$. Also the ODH of n-butane was tested over pristine $\mathrm{TiO}_{2}$, and the obtained results indicated a very poor catalytic activity.

\section{Results}

\subsection{Catalyst Characterization}

3.1.1. X-Ray Diffractions. The X-ray diffraction patterns of pure $\mathrm{TiO}_{2}, \mathrm{VT}$, and LaVT samples were displayed in Figure 1. The solids corresponded to well-crystallized pure phase. The characteristic peak at ca. $2 \theta=25.4^{\circ}$ corresponding to (101) 
TABLE 1: Results of physicochemical characterization of studied samples.

\begin{tabular}{lccc}
\hline Samples & $S_{\text {BET }}\left(\mathrm{m}^{2} / \mathrm{g}\right)$ & $\mathrm{NH}_{3}$ desorption $\left(\mathrm{cm}^{3} / \mathrm{g}\right)$ & $\mathrm{H}_{2}$ consumption \\
\hline VT & 27 & 4.33 & 28.67 \\
LaVT & 11 & 3.72 & 38.18 \\
\hline
\end{tabular}

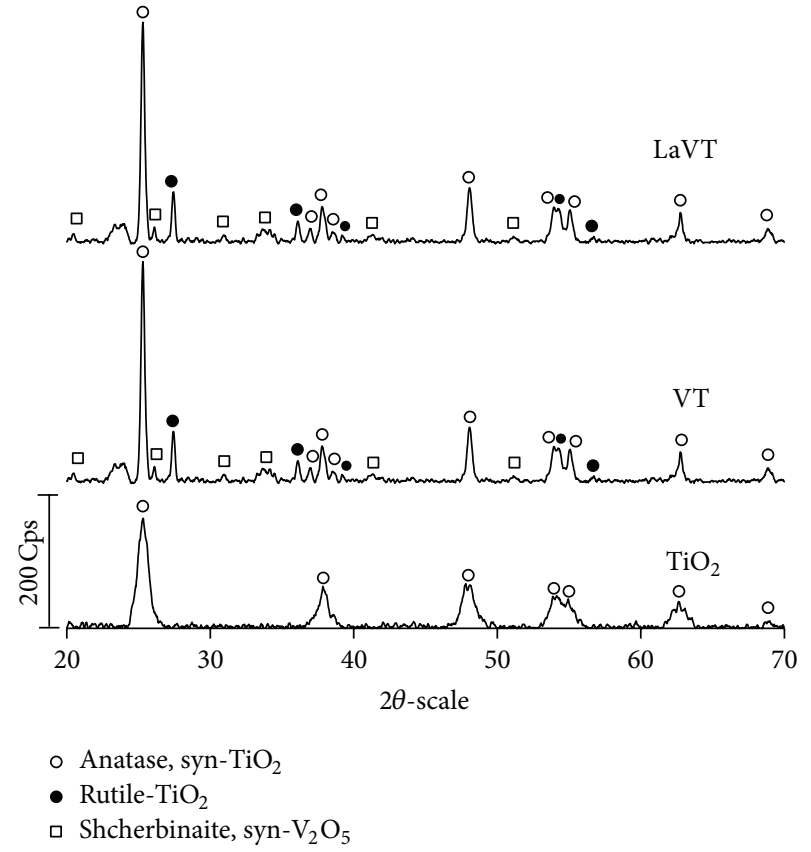

FIgUre 1: XRD patterns of $\mathrm{TiO}_{2}$, VT, and LaVT samples.

plane of anatase phase is clearly observed in all samples. For the pure one, no peak brookite phases of $\mathrm{TiO}_{2}$ are observed, and peak for rutile is also hardly seen. However, weak peaks for rutile are clearly detected in XRD pattern of VT and LaVT samples indicating an interaction between active phase and the support. As it can be seen, for VT and LaVT catalysts, crystalline $\mathrm{V}_{2} \mathrm{O}_{5}$ was detected, and an increase in the intensity of the anatase reflex, at $25.4^{\circ}$, can be observed. This phenomenon has already been observed [20]. That is, when vanadium is not uniformly dispersed on the surface it promoted the formation of anatase crystallites during the catalyst calcination. Sample with low lanthanum loading did not show any diffraction lines corresponding to La-containing compound suggesting that XRD analysis cannot give information about the molecular dispersion of $\mathrm{La}$ species.

3.1.2. BET Measurements. The characteristic properties of the catalytic materials prepared are shown in Table 1. It was found that the modification of parent samples did not significantly change the structure of these materials. The changes in $S_{\mathrm{BET}}$ illustrate a pronounced reduction of the surface due to the vanadium oxide impregnation. The surface area of the samples varied from $56 \mathrm{~m}^{2} / \mathrm{g}$ (parent $\mathrm{TiO}_{2}$ ) to $27 \mathrm{~m}^{2} / \mathrm{g}$ for VT and to $11 \mathrm{~m}^{2} / \mathrm{g}$ for LaVT. This could be explained as follows: at high calcination temperature, big crystallites of $\mathrm{V}_{2} \mathrm{O}_{5}$ and additional crystalline $\mathrm{LaVO}_{4}$ were formed. The formation of crystalline $\mathrm{V}_{2} \mathrm{O}_{5}$ as well as vanadate of La could be a reason for the drastic decrease of BET surface areas. However, the process of phase separation, being associated with a loss of specific surface area, could not be suppressed by doping with $\mathrm{La}$, and thus La has no stabilising influence on the $\mathrm{V}$ centres.

3.1.3. UV-Vis Spectra. The UV-Vis spectroscopy provides information about the character and oxidation state of vanadium. The obtained UV-Vis spectra for both prepared samples are presented in Figure 2. For quantitative analysis of all types of surface vanadium complexes, the spectra were deconvoluted into individual bands. The deconvolution spectra, using symmetric Gaussian curves, showed that bands related to the tetrahedral and octahedral species were observed for all solids. The octahedral species were related to $\mathrm{V}^{5+}$ ions which present characteristic absorption bands between 350 and $500 \mathrm{~nm}$, while highly dispersed tetrahedral species of $\mathrm{V}^{5+}$ could be related to contributions between 280 and $340 \mathrm{~nm}[15,16]$. In present work, we suggest that the bands observed at $244.3 \mathrm{~nm}$ (for VT) and $246.1 \mathrm{~nm}$ (for LaVT) correspond to titanium ions in octahedral coordination [28]. The band at $218 \mathrm{~nm}$ originated from isolated $\mathrm{VO}_{4}$ tetrahedra. For VT catalyst, absorption bands around $300-350 \mathrm{~nm}$ can be assigned to charge transfer transitions of tetrahedrally coordinated $\mathrm{V}^{5+}$ species $[15,16]$. But the position of the third band $(336.4 \mathrm{~nm})$ suggested that the $\mathrm{VO}_{x}$ species are low oligomeric $\mathrm{VO}_{4}$ tetrahedra rather than isolated. The band at $400-430 \mathrm{~nm}$ pointed to the presence of $\mathrm{V}^{5+}$ in octahedral coordination. The small absorption around 480 originates most likely from some polymeric octahedrally coordinated vanadium sites. Low intensity of this band suggested that the octahedral $\mathrm{V}$ species play only a minor role in this material.

The UV-Vis spectrum of the La-doped $\mathrm{V} / \mathrm{TiO}_{2}$ catalyst was quite similar to that of the undoped one. However the relative intensity of the band around $300-350 \mathrm{~nm}$ was lower than that in the undoped suggesting that tetrahedral $\mathrm{V}$ centres might also be polymerized lower than La-free sample. Moreover the relative intensity of the band around $450 \mathrm{~nm}$, indicating the presence of higher coordinated $\mathrm{V}$ species, is much higher than that in undoped $\mathrm{VO}_{x} / \mathrm{TiO}_{2}$ sample, and its relative intensity with respect to the overall UV-vis intensity was the highest in comparison to other bands. This indicates that La does not support the dispersion of $\mathrm{V}$ sites.

3.1.4. $\mathrm{H}_{2}$-TPR Spectra. The reducibility of the catalysts was measured by means of $\mathrm{H}_{2}$-TPR. The $\mathrm{H}_{2}$-TPR of VT and LaVT were plotted in Figure 3. For comparison, the $\mathrm{H}_{2}$-TPR profiles of parent $\mathrm{TiO}_{2}$ and pure $\mathrm{V}_{2} \mathrm{O}_{5}$ were also plotted. It is clear that $\mathrm{TiO}_{2}$ was hardly reduced at the temperatures lower than $800^{\circ} \mathrm{C}$. In pure $\mathrm{V}_{2} \mathrm{O}_{5}$ the first reduction peak appeared at above $600^{\circ} \mathrm{C}$. However lower reduction temperatures were 


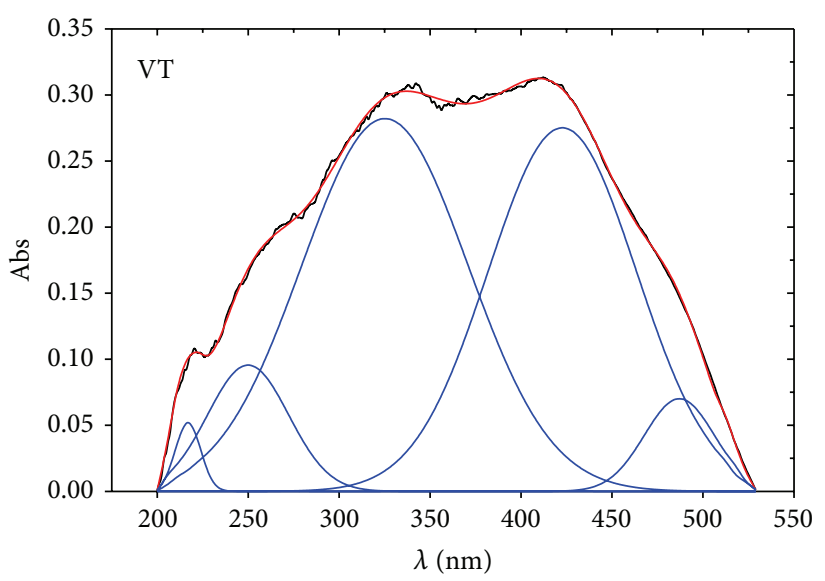

(a)

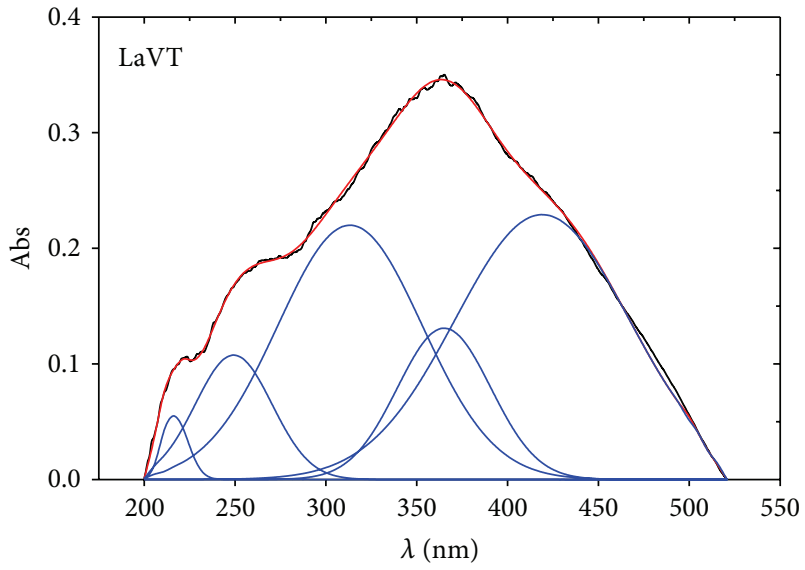

(b)

FIgURE 2: UV-Vis spectra of VT (a) and LaVT (b).

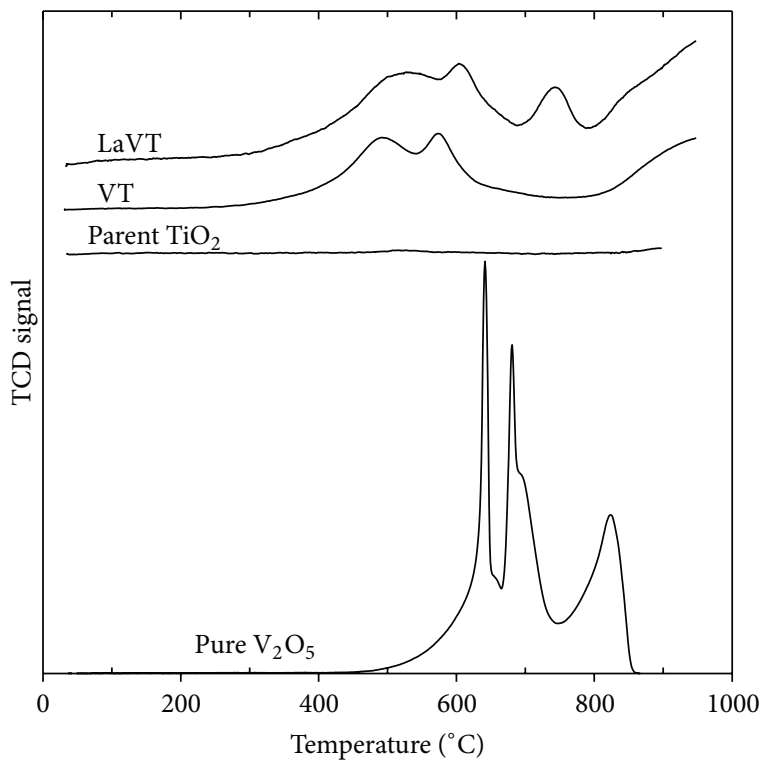

FIgURE 3: A comparison of $\mathrm{H}_{2}$-TPR spectra obtained for LaVT, VT, parent $\mathrm{TiO}_{2}$, and pure $\mathrm{V}_{2} \mathrm{O}_{5}$.

observed in VT and LaVT catalyst samples indicating the interaction between active sites and the support.

The deconvolutions of $\mathrm{H}_{2}$-TPR profiles of VT and LaVT were shown in Figure 4. The TPR profiles of VT and LaVT consisted of several peaks. This points to the presence of different $\mathrm{VO}_{x}$ species, differing in their reduction stability, and is in agreement with the results of UV-Vis and XRD. The existence of $\mathrm{VO}_{4}$ isolated species was confirmed by TPR of the studied samples. According in the literature [7] the first reduction peak is ascribable to the reduction of surface $\mathrm{V}^{5+}$ species in distorted $\mathrm{VO}_{4}$ species while the high temperature would correspond to the reduction of $\mathrm{V}^{5+}$ belonging to the bulk orthovanadate. In VT the TPR deconvolution showed reduction peaks centred at $496.4^{\circ} \mathrm{C}$ and $570.9^{\circ} \mathrm{C}$. In LaVT these peaks shifted to higher temperatures $528^{\circ} \mathrm{C}$ and $608^{\circ} \mathrm{C}$.
In the same order, the vanadium dispersion decreased owing to a dramatic loss of surface area, which favours the formation of polymerised $\mathrm{V}$ species or even crystalline vanadates of La. Therefore, the TPR results indicated that less polymerised vanadium species can be move easily reduced than $\mathrm{V}$ centres in condensed phases. The peaks appearing at around $743^{\circ} \mathrm{C}$ for $\mathrm{LaVT}$ and $628^{\circ} \mathrm{C}$ for VT arose probably from the reduction of crystalline $\mathrm{V}_{2} \mathrm{O}_{5}$ and $\mathrm{LaVO}_{4}$ [29].

3.1.5. $\mathrm{NH}_{3}-\mathrm{TPD}$. The surface acidic properties of VT and LaVT samples investigated by $\mathrm{NH}_{3}$-PTD were compiled in Figure 5. The $\mathrm{NH}_{3}$ desorption patterns which indicated acid sites of weak and moderate strengths were present on the catalysts. However, the presence of La decreased the moderate acid sites, and also the total $\mathrm{NH}_{3}$ desorption in LaVT sample $(3.72 \mathrm{~mL} / \mathrm{g}$ catalyst) was lower than that in VT sample ( $4.33 \mathrm{~mL} \mathrm{NH}_{3} / \mathrm{g}$ catalyst). The obtained results suggested that the surface acidity of the LaVT sample was diminished by La doping.

\subsection{Catalytic Tests for n-Butane Oxidative Dehydrogenation}

3.2.1. Catalytic Activity. Table 2 shows conversion of $\mathrm{n}$ butane and the distribution of reaction products, obtained at each temperature over VT and LaVT catalysts. For comparison, the conversion of n-butane over pristine $\mathrm{TiO}_{2}$ and bulk $\mathrm{V}_{2} \mathrm{O}_{5}$ is also presented, but the obtained conversions can be negligible. Figure 6 shows the variation in n-butane conversion and total alkene's selectivity with the reaction temperature.

From data reported in Table 2 the major products formed under reaction conditions with $10 \% \mathrm{O}_{2}$ as coreactant were 1-butene (1-b), tran-2-butene (2-trans), cis-2-butene (2cis), butadiene, $\left(\mathrm{C}_{4}-1,3\right) \mathrm{CO}_{2}, \mathrm{CO}$, and cracking products (methane, ethane, ethane, and propene). It is possible to observe an effect of the support on the activities and selectivities of vanadium based catalysts in the ODH of $n$ butane in agreement with the observations of many different 


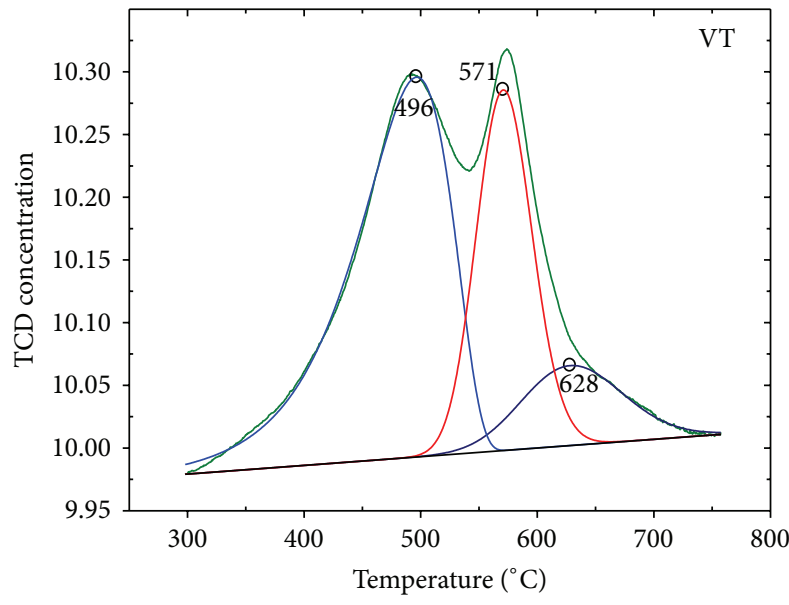

(a)

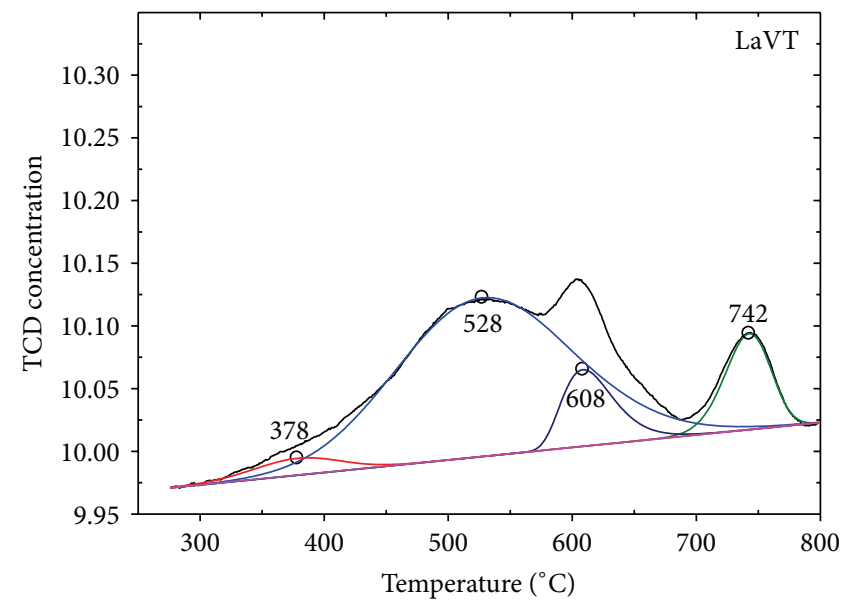

(b)

FIGURE 4: $\mathrm{H}_{2}$-TPR profiles of VT (a) and LaVT (b) catalysts.

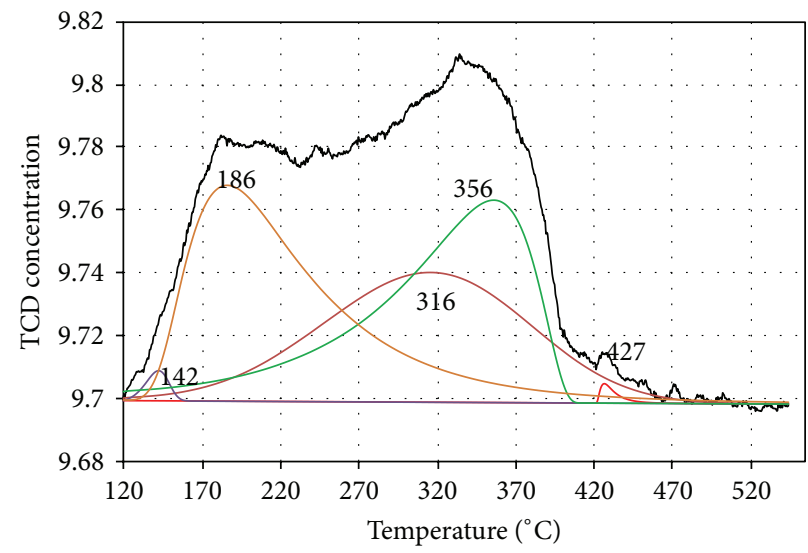

(a)

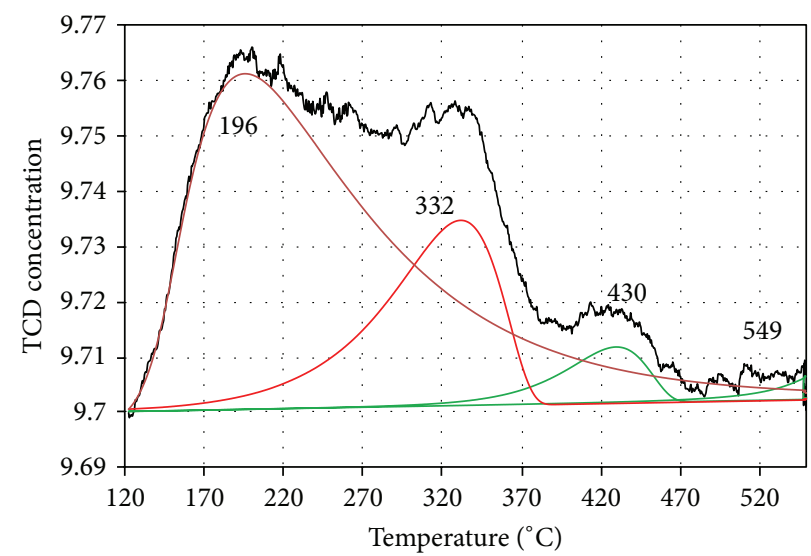

(b)

FIGURE 5: $\mathrm{NH}_{3}$-temperature programmed desorption profiles of the catalytic samples: (a) VT; (b) LaVT.

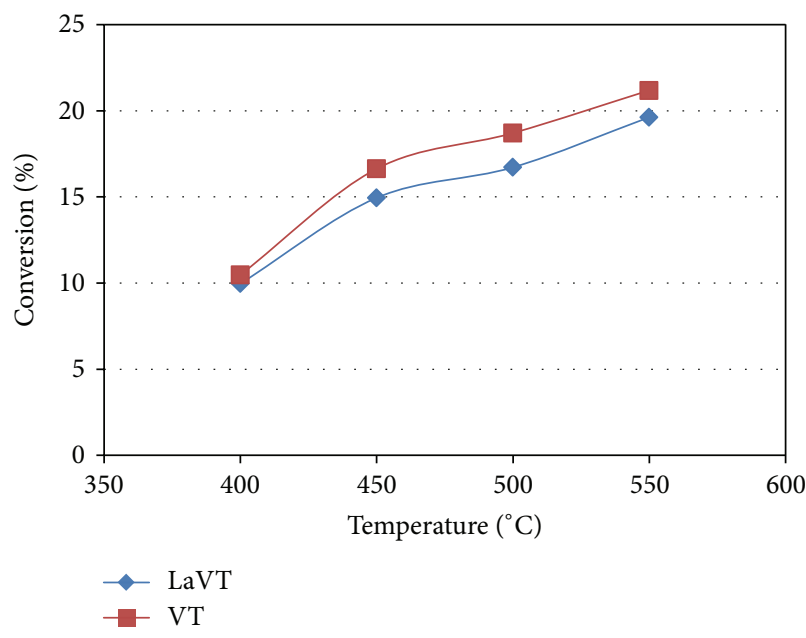

(a)

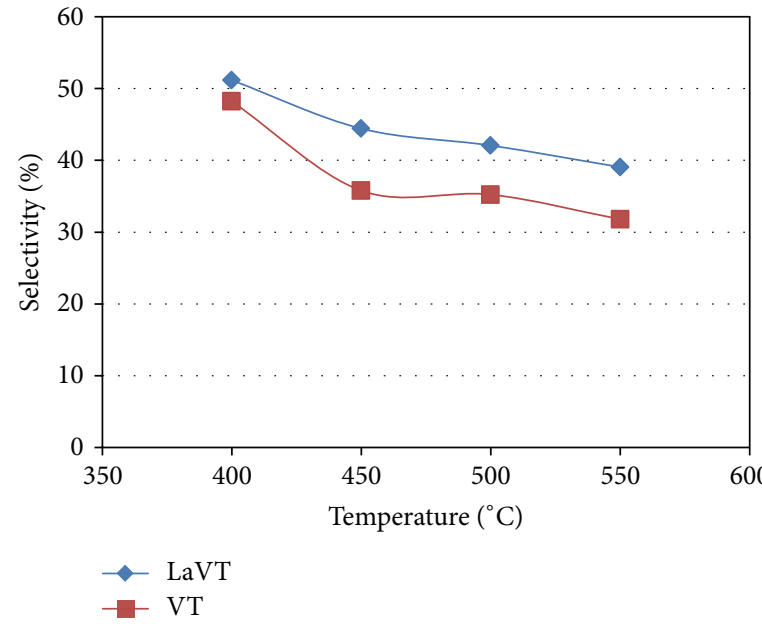

(b)

FIGURE 6: Conversion (a) and total alkene's selectivity (b) as functions of reaction temperature for VT and LaVT. 
TABLE 2: Results of catalytic tests in $\mathrm{ODH}$ of n-butane $\left(\mathrm{C}_{4} \mathrm{H}_{10} / \mathrm{O}_{2} / \mathrm{N}_{2}=30 / 10 / 60\right.$ vol. \%, total flow rate $\left.32 \mathrm{~mL} / \mathrm{min}\right)$.

\begin{tabular}{|c|c|c|c|c|c|c|c|}
\hline $\mathrm{T}\left({ }^{\circ} \mathrm{C}\right)$ & Catalyst & Conv. (\%) & $1-b$ & 2-trans & 2-cis & $\mathrm{C}_{4}-1,3$ & $\mathrm{CO}_{x}$ \\
\hline \multirow{4}{*}{400} & $\mathrm{LaVT}$ & 9.97 & 24.99 & 15.42 & 10.73 & 0 & 26.43 \\
\hline & VT & 10.48 & 27.11 & 13.13 & 7.96 & 0 & 25.02 \\
\hline & Parent $\mathrm{TiO}_{2}$ & Not observed & & & & & \\
\hline & Bulk $\mathrm{V}_{2} \mathrm{O}_{5}$ & Not observed & & & & & \\
\hline \multirow{4}{*}{450} & LaVT & 14.95 & 19.83 & 14.29 & 10.28 & 0 & 21.15 \\
\hline & VT & 16.64 & 18.67 & 9.30 & 5.80 & 0 & 19.70 \\
\hline & Parent $\mathrm{TiO}_{2}$ & Not observed & & & & & \\
\hline & Bulk $\mathrm{V}_{2} \mathrm{O}_{5}$ & Not observed & & & & & \\
\hline \multirow{4}{*}{500} & LaVT & 16.72 & 19.66 & 12.01 & 8.42 & 1.96 & 19.17 \\
\hline & VT & 18.71 & 17.59 & 9.42 & 6.22 & 1.38 & 19.34 \\
\hline & Parent $\mathrm{TiO}_{2}$ & Not observed & & & & & \\
\hline & Bulk $\mathrm{V}_{2} \mathrm{O}_{5}$ & 0.94 & & & & & \\
\hline \multirow{4}{*}{550} & LaVT & 19.63 & 19.87 & 9.99 & 6.68 & 2.52 & 15.77 \\
\hline & VT & 21.19 & 17.96 & 8.57 & 5.25 & 0 & 15.72 \\
\hline & Parent $\mathrm{TiO}_{2}$ & 3.73 & & & & & \\
\hline & Bulk $\mathrm{V}_{2} \mathrm{O}_{5}$ & 5.76 & & & & & \\
\hline
\end{tabular}

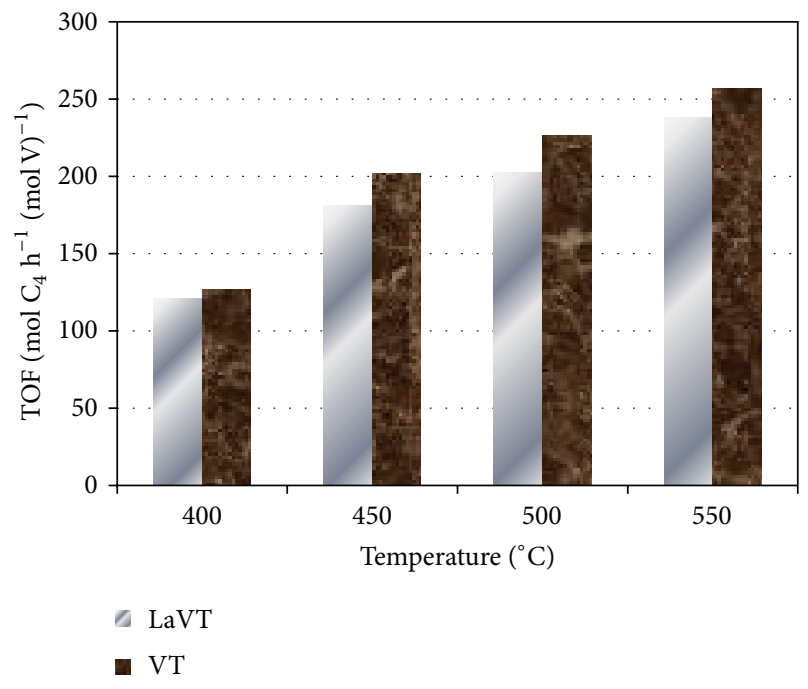

(a)

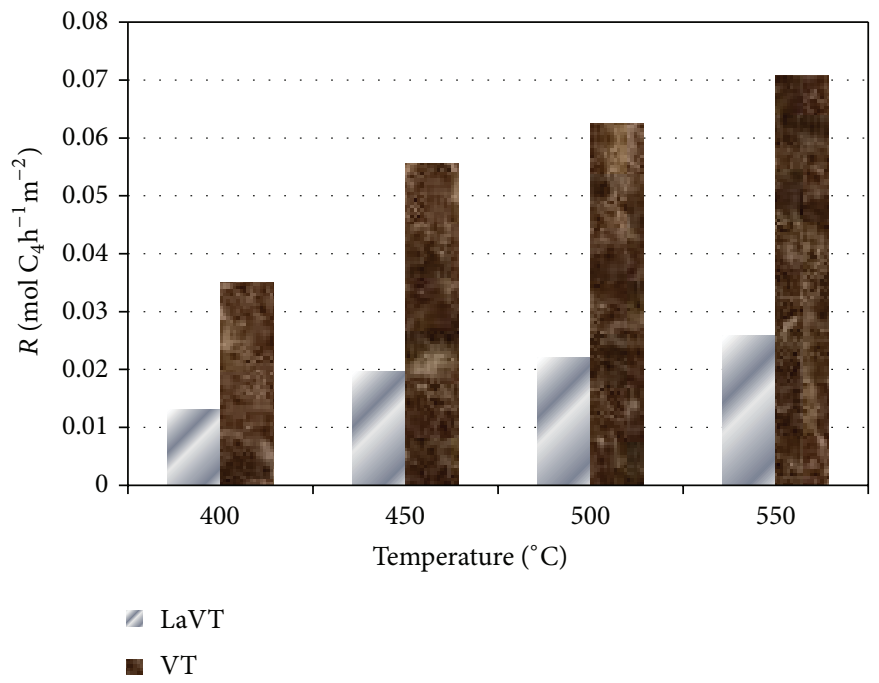

(b)

FIgURE 7: Variation of turnover (in $\mathrm{mol} \mathrm{C}_{4} \mathrm{~h}^{-1}(\mathrm{molV})^{-1}$ ) and the specific rate (in $\mathrm{mol} \mathrm{C}_{4} \mathrm{~h}^{-1} \mathrm{~m}^{-2}$ ) with undoped and $\mathrm{La}^{-} \mathrm{doped}_{\mathrm{VO}} / \mathrm{TiO}_{2}$.

authors reported in the literature [30]. Generally, the conversions increase with the temperature, whereas the selectivities decrease, as usual, with the conversion. Also, it was demonstrated that [20] the activity of the dispersed catalysts can be roughly related to the vanadium load. Santacesaria et al. [20] reported a conversion of $3.2 \%$ and corresponding selectivity of $51.1 \%$ obtained for the ODH of $n$-butane over a $5 \% \mathrm{~V} / \mathrm{TiO}_{2}$ catalyst at $500^{\circ} \mathrm{C}$. However, their experimental conditions differed from those in this work: the content of $\mathrm{V}$ was $5 \%$ (wt.), and catalyst weight was $0.05 \mathrm{~g}$ (meanwhile they are $15 \%$ and $0.2 \mathrm{~g}$, resp., in this work); in their work, the total feed low rate was $150 \mathrm{~mL} / \mathrm{min}$, and $\mathrm{O}_{2} / \mathrm{C}_{4} \mathrm{H}_{10}$ ratio was 1.7. Therefore the differences in catalytic behaviour between our samples and theirs are quite reasonable.
It can be seen that, at the same vanadium loading, although La-free $\mathrm{VO}_{x} / \mathrm{TiO}_{2}(\mathrm{VT})$ catalyst is slightly less selective than the respective $\mathrm{VO}_{x} \mathrm{La} / \mathrm{TiO}_{2}(\mathrm{LaVT})$ sample in the studied temperature range $\left(400-550^{\circ} \mathrm{C}\right)$, it is slightly more active (in terms of butane conversion) than the LaVT. It can be readily seen in Figure 7 that the intrinsic activity evidenced by surface area specific rates $(R)$ and the corresponding turnover of the catalysts have a tendency to increase with the temperature. Moreover it can be seen that LaVT presented a lower activity compared to that of VT catalyst. This trend points to a decreasing number of ODH sites with LaVT. Since present characterizations of the materials indicated higher crystallinities in LaVT than in VT, the trend of turnover values and specific activities in Figure 7 was consistent with 


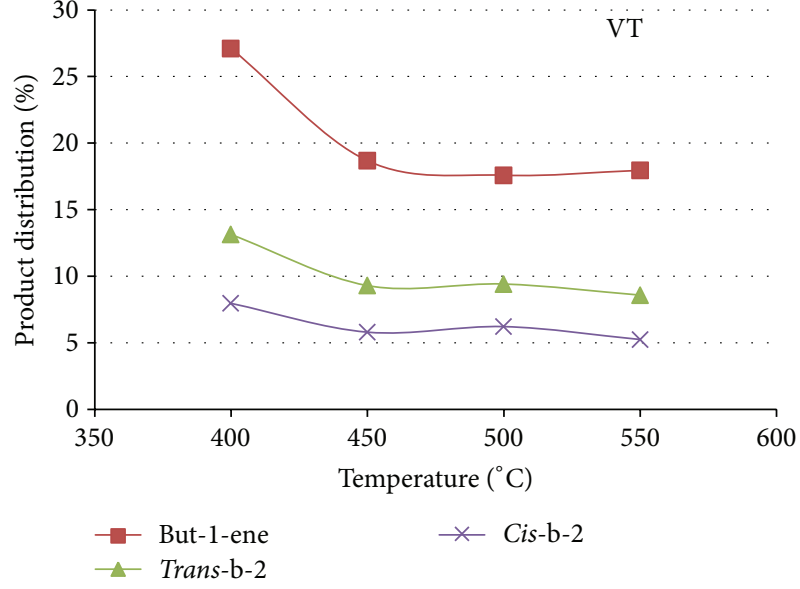

(a)

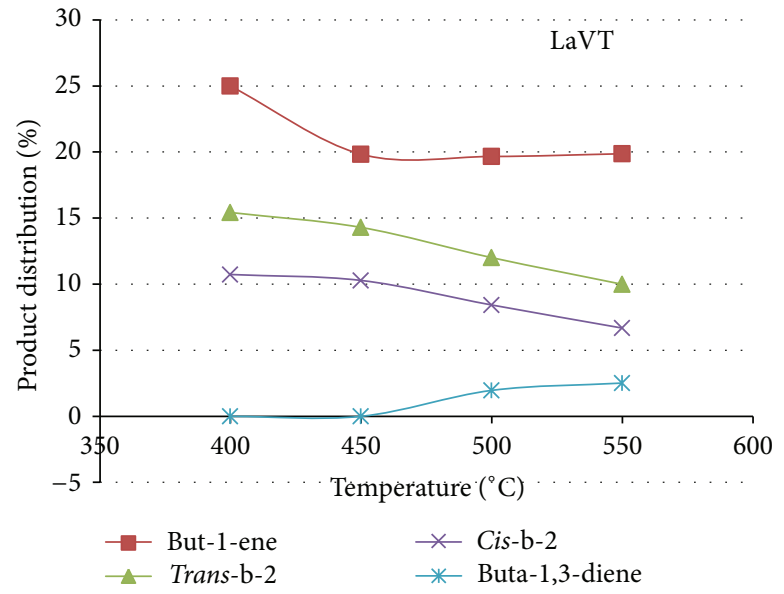

(b)

FIGURE 8: The distribution of alkene's products with the reaction temperatures.

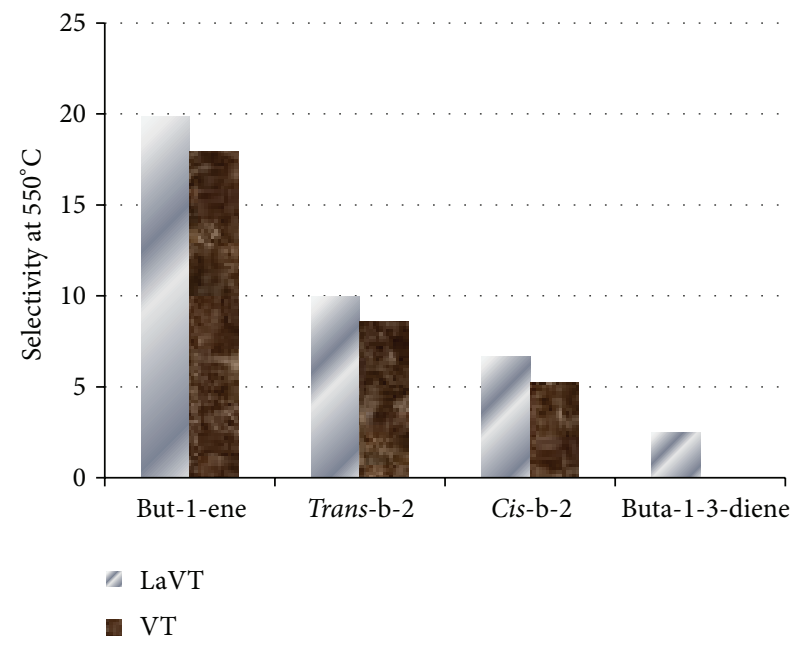

FIGURE 9: Product selectivity over VT and LaVT catalysts at $550^{\circ} \mathrm{C}$.

an inverse relationship between crystallinity and turnover and specific activity.

3.2.2. Product's Distribution. Variation of the selectivity to the main reaction products as a function of temperature on both samples was presented in Table 2. Results in Table 2 showed that over both catalyst samples $\mathrm{CO}_{2}$ and $\mathrm{CO}$ were formed at low butane conversion. This is in agreement with the reports of Murgia et al. [15]. Products $\mathrm{CO}_{x}$ were slightly decreased as conversion increased. Figures 8 and 9 plot the product distrubitions against reaction temperatures. For VT sample the main reaction product was 1-butene in the whole range of studied temperatures while no measurable selectivity toward butadiene was found. Dias et al. [7] studied ODH of $\mathrm{n}$-butane over $\mathrm{Mg}-\mathrm{V}$ catalysts and showed that 1-butene was a main product; however for higher reaction temperatures (above $748 \mathrm{~K}$ ) butadiene was a major product. The selectivity towards 2-butenes was always lower than selectivity towards 1-butene. Similar results were observed by Murgia et al. [15] and Jackson and Rugmini [9]. The ratio tran/cis was approximately constant and equal to 1.42 . An analogous ratio for the $\mathrm{ODH}$ of n-butane over $5 \mathrm{wt} . \% \mathrm{~V}_{2} \mathrm{O}_{5} / \mathrm{TiO}_{2}$ was reported by Santacesaria et al. [20]. Figures 6 and 8 showed that the selectivity towards butenes decreased as conversion increased due to the consecutive reactions. Similar trends are observable for other catalysts reported in the literature $[16,20]$; that is, conversion increases with the residence time, while selectivity to alkene products decreases.

The catalytic behaviour of LaVT sample was similar to VT sample. Taking into account the surface acidity of the samples, the LaVT exposed a higher selectivity than VT. The reaction products distribution was approximately the same: 1-butene was the main product, and the ratio trans/cis was constant and equal to 1.6. Especially, LaVT produced butadiene. Butadiene was formed by consecutive reactions, and competition due to carbon oxide formation from both butyl radicals and butenes [31].

Figure 9 shows the selectivities of alkenes over LaVT and VT catalysts samples at $550^{\circ} \mathrm{C}$. It can be seen that the LaVT has a slightly higher selectivity of alkenes than VT.

The catalytic behaviour of LaVT sample could be attributed to the following.

(i) Doping La resulted in an increase in basicity of catalyst sample (TPD- $\mathrm{NH}_{3}$ results), and it was expected that this change will affect the catalyst selectivity but not the activity. The best selectivity induced by the presence of $\mathrm{La}_{2} \mathrm{O}_{3}$ is a well-known phenomenon described in the literature [27]. Hoang et al. [27] studying the $\mathrm{ODH}$ of isobutane over chromium oxide base catalysts indicated that, when $\mathrm{La}_{2} \mathrm{O}_{3}$ is present in the support, the activity is low, but the selectivity was almost $100 \%$.

(ii) The presence of La species lowers the surface area and thus also the surface vanadium dispersion due to blocking active sites (BET measurement and UV-Vis 
spectra) and increased reduction temperatures (TPR$\mathrm{H}_{2}$ results). These may have a negative effect on the catalytic performance of VT catalyst.

\section{Conclusions}

$\mathrm{V}$ catalysts supported on titania at exceeding theoretical monolayer coverage and doping with lanthanum were tested in the oxidative dehydrogenation of n-butane. In the tested conditions 1-butene was the main reaction products. Characterization of the materials showed that $\mathrm{VO}_{x}$ surface species are well dispersed on the support surface. Acidity measurements revealed that the catalyst samples possess acid sites of weak and moderate strengths. La-containing $\mathrm{VO}_{x} / \mathrm{TiO}_{2}$ exhibited lower acidity than La-free $\mathrm{VO}_{x} / \mathrm{TiO}_{2}$ one, and doping with lanthanum did not improve the catalytic performance of VT catalyst. The low activity could be explained with the lower dispersion of $\mathrm{VO}_{x}$ species in this sample since it favours the agglomeration of $\mathrm{V}$ sites. Despite the observation that lanthanum-doping improved slightly the butene selectivies due to lowered surface acidity, this could not improve the yields of butene. Therefore, it seems likely that improvement of the butene yields in the $\mathrm{ODH}$ of n-butane could be achieved using catalysts with highly dispersed, preferably tetrahedrally coordinated $\mathrm{VO}_{x}$ species, supported on nonacidic materials with high surface area.

\section{Acknowledgments}

This work was supported by National Foundation for Science and Technology Development Vietnam (NAFOSTED) under Project no. 104.03-2010.39.

\section{References}

[1] K. Chen, A. T. Bell, and E. Iglesia, “The relationship between the electronic and redox properties of dispersed metal oxides and their turnover rates in oxidative dehydrogenation reactions," Journal of Catalysis, vol. 209, no. 1, pp. 35-42, 2002.

[2] R. Grabowski and J. Sloczynski, "Kinetics of oxidative dehydrogenation of propane and ethane on $\mathrm{VOx} / \mathrm{SiO}_{2}$ pure and with potassium additive," Chemical Engineering and Processing: Process Intensification, vol. 44, no. 10, pp. 1082-1093, 2005.

[3] Y. M. Liu, W. L. Feng, T. C. Li et al., "Structure and catalytic properties of vanadium oxide supported on mesocellulous silica foams (MCF) for the oxidative dehydrogenation of propane to propylene," Journal of Catalysis, vol. 239, no. 1, pp. 125-136, 2006.

[4] S. Sugiyama, Y. Hiratab, K. Nakagawa et al., "Application of the unique redox properties of magnesium ortho-vanadate incorporated with palladium in the unsteady-state operation of the oxidative dehydrogenation of propane," Journal of Catalysis, vol. 260, no. 1, pp. 157-163, 2008.

[5] E. Heracleous and A. A. Lemonidou, "Homogeneous and heterogeneous pathways of ethane oxidative and non-oxidative dehydrogenation studied by temperature-programmed reaction," Applied Catalysis A, vol. 269, no. 1-2, pp. 123-135, 2004.

[6] E. A. Mamedov and V. C. Corberán, "Oxidative dehydrogenation of lower alkanes on vanadium oxide-based catalysts. The present state of the art and outlooks," Applied Catalysis A, vol. 127, no. 1-2, pp. 1-40, 1995.
[7] A. P. S. Dias, L. D. Dimitrov, M. C. R. Oliveira, R. Zǎvoianu, A. Fernandes, and M. F. Portela, "Oxidative dehydrogenation of butane over substoichiometric magnesium vanadate catalysts prepared by citrate route," Journal of Non-Crystalline Solids, vol. 356, no. 28-30, pp. 1488-1497, 2010.

[8] Z. Wu, H. S. Kim, P. C. Stair, S. Rugmini, and S. D. Jackson, "On the structure of vanadium oxide supported on aluminas: UV and visible Raman spectroscopy, UV-visible diffuse reflectance spectroscopy, and temperature-programmed reduction studies," Journal of Physical Chemistry B, vol. 109, no. 7, pp. 27932800, 2005.

[9] S. D. Jackson and S. Rugmini, "Dehydrogenation of n-butane over vanadia catalysts supported on $\theta$-alumina," Journal of Catalysis, vol. 251, no. 1, pp. 59-68, 2007.

[10] J. M. Kanervo, M. E. Harlin, A. O. I. Krause, and M. A. Bañares, "Characterisation of alumina-supported vanadium oxide catalysts by kinetic analysis of H2-TPR data," Catalysis Today, vol. 78, no. 1-4, pp. 171-180, 2003.

[11] A. A. Lemonidou and A. E. Stambouli, "Catalytic and noncatalytic oxidative dehydrogenation of n-butane," Applied Catalysis A, vol. 171, no. 2, pp. 325-332, 1998.

[12] F. Gilardoni, A. T. Bell, A. Chakraborty, and P. Boulet, "Density functional theory calculations of the oxidative dehydrogenation of propane on the (010) surface of $\mathrm{C}_{2} \mathrm{O}_{5}$," Journal of Physical Chemistry B, vol. 104, no. 51, pp. 12250-12255, 2000.

[13] E. Heracleous, M. Machli, A. A. Lemonidou, and I. A. Vasalos, "Oxidative dehydrogenation of ethane and propane over vanadia and molybdena supported catalysts," Journal of Molecular Catalysis A, vol. 232, no. 1-2, pp. 29-39, 2005.

[14] T. Blasco and J. M. López Nieto, "Oxidative dehydrogenation of short chain alkanes on supported vanadium oxide catalysts," Applied Catalysis A, vol. 157, no. 1-2, pp. 117-142, 1997.

[15] V. Murgia, E. M. F. Torres, J. C. Gottifredi, and E. L. Sham, "Sol-gel synthesis of $\mathrm{VO}_{2} \mathrm{O}_{5}-\mathrm{SiO}_{2}$ catalyst in the oxidative dehydrogenation of n-butane," Applied Catalysis A, vol. 312, pp. 134-143, 2006.

[16] V. Iannazzo, G. Neri, S. Galvagno, M. Di Serio, R. Tesser, and E. Santacesaria, "Oxidative dehydrogenation of isobutane over $\mathrm{V}_{2} \mathrm{O}_{5}$-based catalysts prepared by grafting vanadyl alkoxides on $\mathrm{TiO}_{2}-\mathrm{SiO}_{2}$ supports," Applied Catalysis A, vol. 246, no. 1, pp. 4968, 2003.

[17] A. Klisińska, K. Samson, I. Gressel, and B. Grzybowska, "Effect of additives on properties of $\mathrm{V}_{2} \mathrm{O}_{5} / \mathrm{SiO}_{2}$ and $\mathrm{V}_{2} \mathrm{O}_{5} / \mathrm{MgO}$ catalysts. I: oxidative dehydrogenation of propane and ethane," Applied Catalysis A, vol. 309, no. 1, pp. 10-16, 2006.

[18] Y. Fu, H. Ma, Z. Wang, W. Zhu, T. Wu, and G. J. Wang, "Characterization and reactivity of $\mathrm{SnO}_{2}$-doped $\mathrm{V}_{2} \mathrm{O}_{5} / \gamma-\mathrm{Al}_{2} \mathrm{O}_{3}$ catalysts in dehydrogenation of isobutane to isobutene," Journal of Molecular Catalysis A, vol. 221, no. 1-2, pp. 163-168, 2004.

[19] J. D. Pless, B. B. Bardin, H. S. Kim et al., "Catalytic oxidative dehydrogenation of propane over Mg-V/Mo oxides," Journal of Catalysis, vol. 223, no. 2, pp. 419-431, 2004.

[20] E. Santacesaria, M. Cozzolino, M. Di Serio, A. M. Venezia, and R. Tesser, "Vanadium based catalysts prepared by grafting: preparation, properties and performances in the ODH of butane," Applied Catalysis A, vol. 270, no. 1-2, pp. 177-192, 2004.

[21] J. L. Lakshmi, N. J. Ihasz, and J. M. Miller, "Synthesis, characterization and ethanol partial oxidation studies of $\mathrm{V}_{2} \mathrm{O}_{5}$ catalysts supported on $\mathrm{TiO}_{2}-\mathrm{SiO}_{2}$ and $\mathrm{TiO}_{2}-\mathrm{ZrO}_{2}$ sol-gel mixed oxides," Journal of Molecular Catalysis A, vol. 165, no. 1-2, pp. 199-209, 2001. 
[22] A. Galli, J. M. López Nieto, A. Dejoz, and M. I. Vazquez, “The effect of potassium on the selective oxidation of n-butane and ethane over $\mathrm{Al}_{2} \mathrm{O}_{3}$-supported vanadia catalysts," Catalysis Letters, vol. 34, no. 1-2, pp. 51-58, 1995.

[23] A. Corma, J. M. López-Nieto, N. Paredes et al., "Oxidative dehydrogenation of propane over supported-vanadium oxide catalysts," Studies in Surface Science and Catalysis, vol. 72, pp. 213-220, 1992.

[24] B. Grzybowska, P. Mekšs, R. Grabowski, K. Wcisto, Y. Barbaux, and L. Gengembre, "Effect of potassium addition to $\mathrm{V}_{2} \mathrm{O}_{5} / \mathrm{TiO}_{2}$ and $\mathrm{MoO}_{3} / \mathrm{TiO}_{2}$ catalysts on their physicochemical and catalytic properties in oxidative dehydrogenation of propane," Studies in Surface Science and Catalysis C, vol. 82, pp. 151-158, 1994.

[25] K. Mori, A. Miyamoto, and Y. Murakami, "Catalytic reactions on well-characterized vanadium oxide catalysts. 4: oxidation of butane," Journal of Physical Chemistry, vol. 89, no. 20, pp. 42654269, 1985.

[26] J. Haber, A. Kozlowska, and R. Kozłowski, "The structure and redox properties of vanadium oxide surface compounds," Journal of Catalysis, vol. 102, no. 1, pp. 52-63, 1986.

[27] M. Hoang, J. F. Mathews, and K. C. Pratt, "How to get higher selectivity and yields of isobutylene," Chemtech, vol. 29, no. 9, pp. 45-48, 1999.

[28] S. A. Holmes, F. Quignard, A. Choplin, R. Teissier, and J. Kervennal, "Tetraneopentyltitanium derived supported catalysts. Part 1: synthesis and catalytic properties for the epoxidation of cyclohexene with aqueous hydrogen peroxide," Journal of Catalysis, vol. 176, no. 1, pp. 173-181, 1998.

[29] C. T. Au, W. D. Zhang, and H. L. Wan, "Preparation and characterization of rare earth orthovanadates for propane oxidative dehydrogenation," Catalysis Letters, vol. 37, no. 3-4, pp. 241-246, 1996.

[30] M. F. Portela, "Catalytic oxidative dehydrogenation of n-butane," Catalysis Reviews, vol. 44, no. 2, pp. 247-286, 2002.

[31] T. Blasco, J. M. L. Nieto, A. Dejoz, and M. I. Vazquez, "Influence of the acid-base character of supported vanadium catalysts on their catalytic properties for the oxidative dehydrogenation of n-butane," Journal of Catalysis, vol. 157, no. 2, pp. 271-282, 1995. 

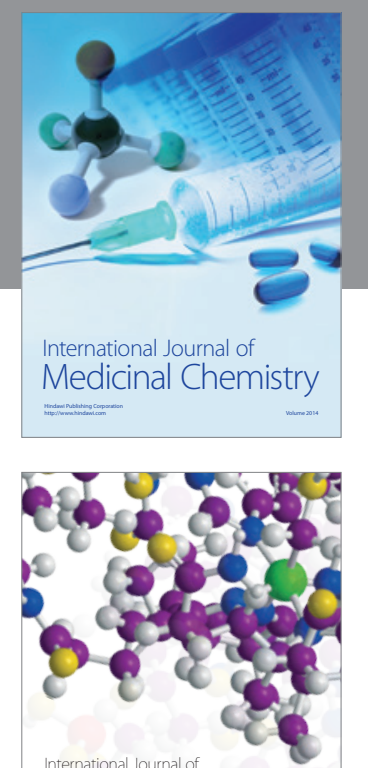

\section{Carbohydrate} Chemistry

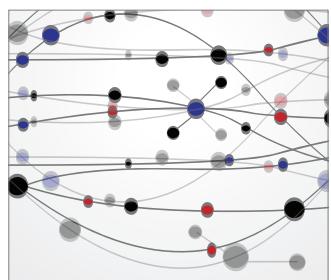

The Scientific World Journal
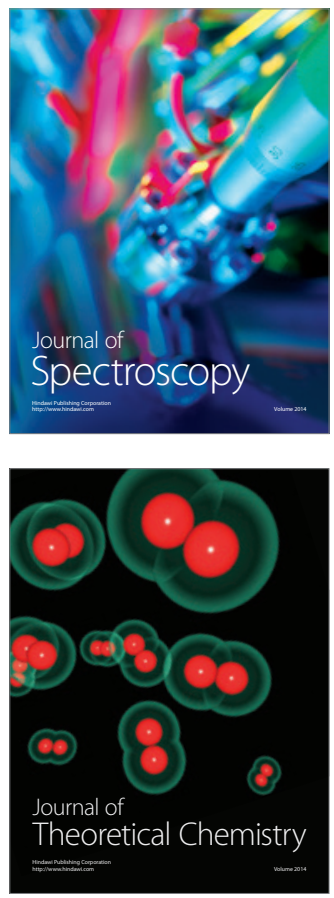
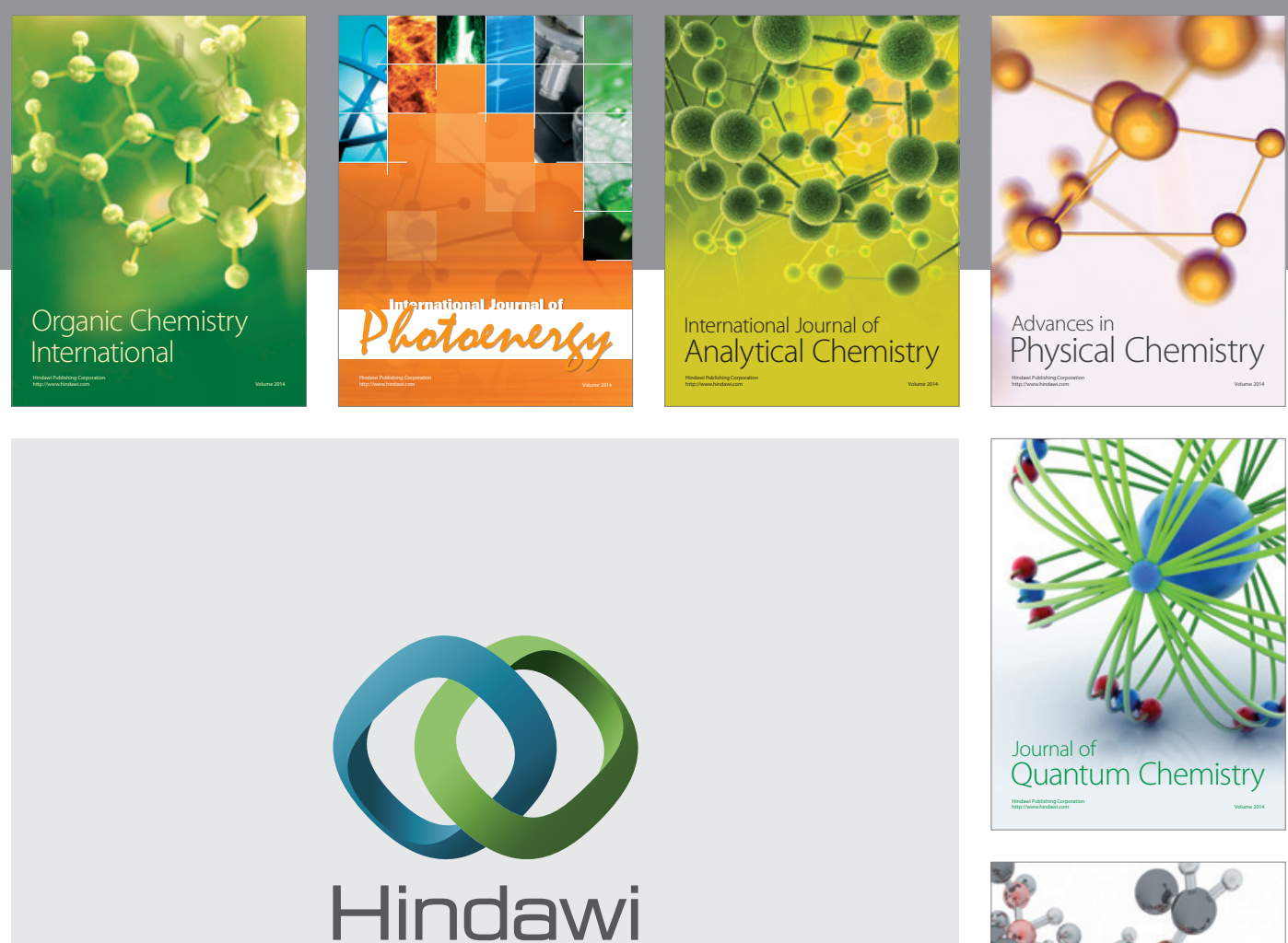

Submit your manuscripts at

http://www.hindawi.com

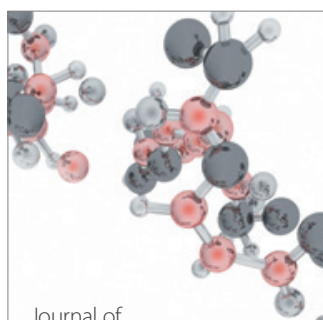

Analytical Methods

in Chemistry

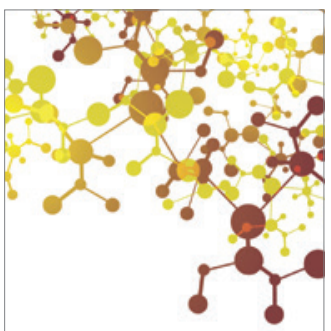

Journal of

Applied Chemistry

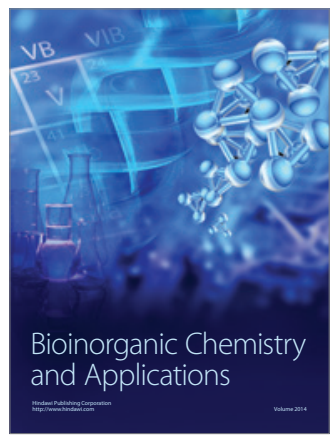

Inorganic Chemistry
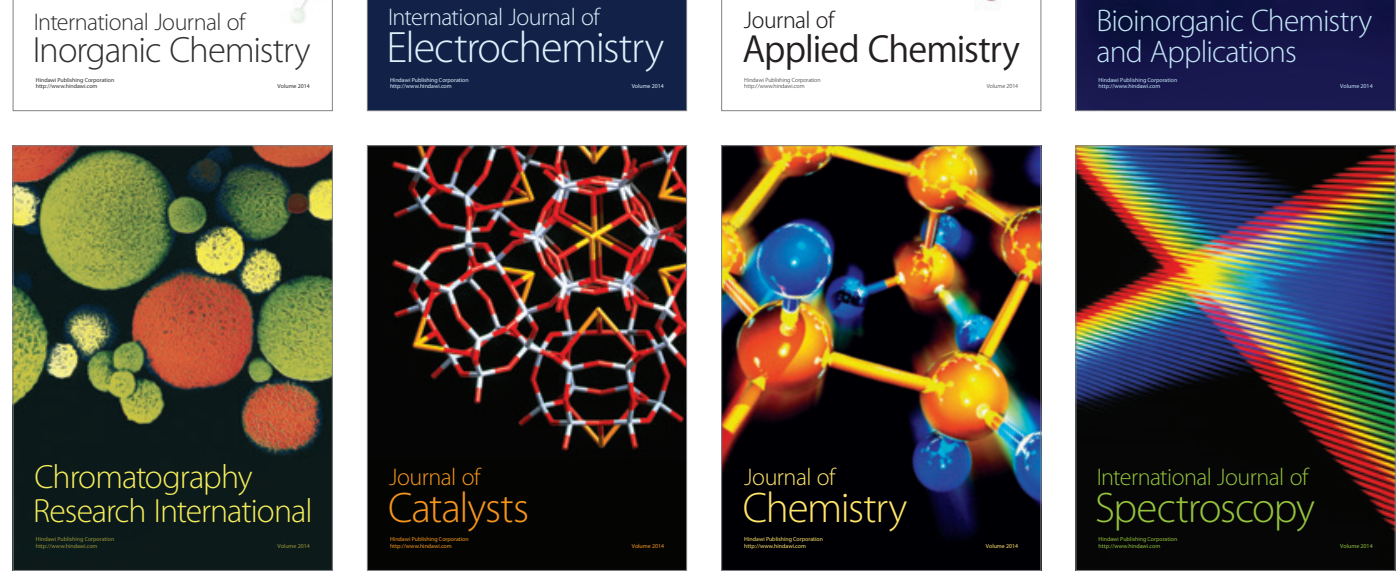